\title{
Light Weight Medium (Pottery Spherical) Cultivation of Plants Used in Green Roof Feasibility Studies

\author{
Chiou-Chuan Chen ${ }^{1,}$ a , Yi-Hong Pengb ${ }^{2}$, Chun-Lin Chen ${ }^{1, b}$, \\ Chiou-Chuan Lee L $^{*}$
}

\author{
${ }^{1}$ Assistant Professor, Chung Chou University of Science and Technology, Department of \\ Landscape Architecture, No.6, Lane2, Sec.3, Shanjiao Rd., Yuanlin Township, Changhua County, \\ Taiwan (R.O.C.). \\ ${ }^{2}$ Master Degree, Cheng Kung University, Department of Architecture, No.1, University Rd, Tainan, \\ Taiwan (R.O.C.) \\ ${ }^{3}$ Assistant Professor, Nan Jeon University of Science and Technology, Department of Construction \\ Engineering, No.178 Chaoqin Rd, Yanshui Dist. Tainan, Taiwan (R.O.C.) \\ aland530308@yahoo.com.tw, bbc0933935146@gmail.com, 'se001@mail.nju.tw
}

Keywords: Green roof, Light-weight medium, Pottery spherical, Plants, Soil loam.

\begin{abstract}
We tested 8 plants and 3 medium and tested pottery spherical base, thus achieving the results.The green coverage for light media S2 (pottery spherical to sandy loam is 8:2) is suitable for Alpinia speciosa the best growth, followed is Zoysia matrella, with Duranta repens as the third. The green coverage for median media S1 (pottery spherical to sandy loam is 5:5) is suitable for Zoysia matrella the best growth, followed is Alpinia speciosa, with Duranta repens as the third. The green coverage for heavy media S0 (pottery spherical to sandy loam is 2:8) is suitable for Duranta repens the best growth, followed is Alpinia speciosa, with Zoysia matrella as the third. Pottery spherical to sandy loam medium is more suitable for Duranta repens, Alpinia speciosa, and Zoysia matrella with growth. The ratio of pottery spherical to sandy loam is $2: 8$, thus increasing the coverage and growth for Duranta repens, Alpinia speciosa, Murraya paniculata, Portulaca grandiflora, Zoysia matrella and Spathoglottis plicata. The prescription, whereby the ratio of pottery spherical to sandy loam is 5:5, is suitable for Duranta repens, Alpinia-speciosa, Portulaca grandiflora, Zoysia matrella, whereby the ratio of pottery spherical to sandy loam is $8: 2$, is suitable for Podocarpus costalis and Liriope platyphylla. The prescriptions, whereby the ratio of light-weight medium is $2: 8$, which is suitable for more kinds of plants. Different media prescriptions are well-grown planting combinations, in which one can choose different plant species based on the environment and in order to create biodiversity.
\end{abstract}

\section{Introduction}

In view of global warming, urban heat island effect, urban ecological corridor, storm water, reduced runoff, and other issues, during the process of land development and construction it has been helpful to start thinking about how a piece of natural land can improve the global environment $[1-5,7,9$,$] . Basic needs include planting a green roof growing media, with the traditional$ construction method employing mostly general soil (loam or sandy loam). However, one may consider reducing the load floor, which can be applied as a lightweight media, to make the body of the load lighter and safer [2-4].

After a site is actually observed and public works are budgeted, one finds that the industry practice is to construct green roofs that are completely waterproofed and to have pavement works on the roof after laying down a non-woven drainage board. The choice of growing media is mostly direct backfill sandy loam. This experiment studies the choice of the current market in order to produce an easily accessible and lighter cultivation medium, instead of using $100 \%$ of the sandy loam. The goal is to achieve lower structural load buildings and provide an ideal environment for the growth of plants [1-4]. 


\section{Materials and Methods}

Empirical Location. Taiwan (Tainan), Cheng Kung University Department of Architecture roof. Empirical Facilities. In this study the choice of plant pots' growing media thickness should be $10 \mathrm{~cm} \sim 15 \mathrm{~cm}[4,8]$, to facilitate the turf and shrub in irrigation water on the growth supplemented where planting is possible. For planting and growth, the average growth of the crown is in a circular manner (Figs. 1-4). Fig. 4 Explanation cultivation containers' for laying drainage board $1.2 \mathrm{~cm}$, non-woven $1 \mathrm{~mm}$, medium(pottery spherical and sandy loam) depth $14.4 \mathrm{~cm}$ of cross-section sketch map.
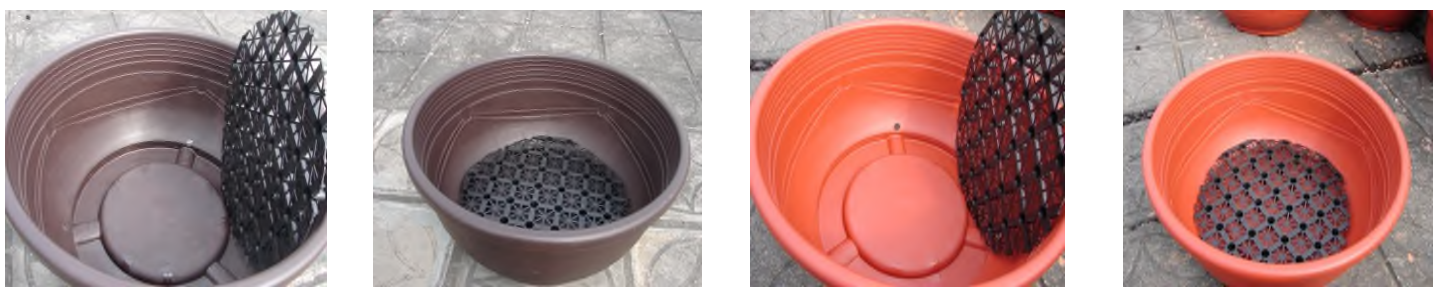

Fig. 1 Plant pot containers.
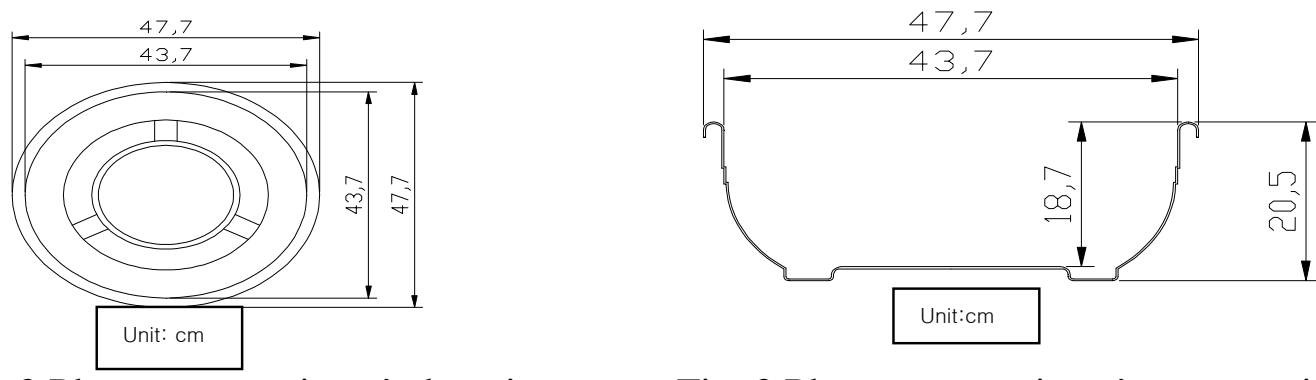

Fig. 2 Plant pot containers' plan view.

Fig. 3 Plant pot containers' cross-section.

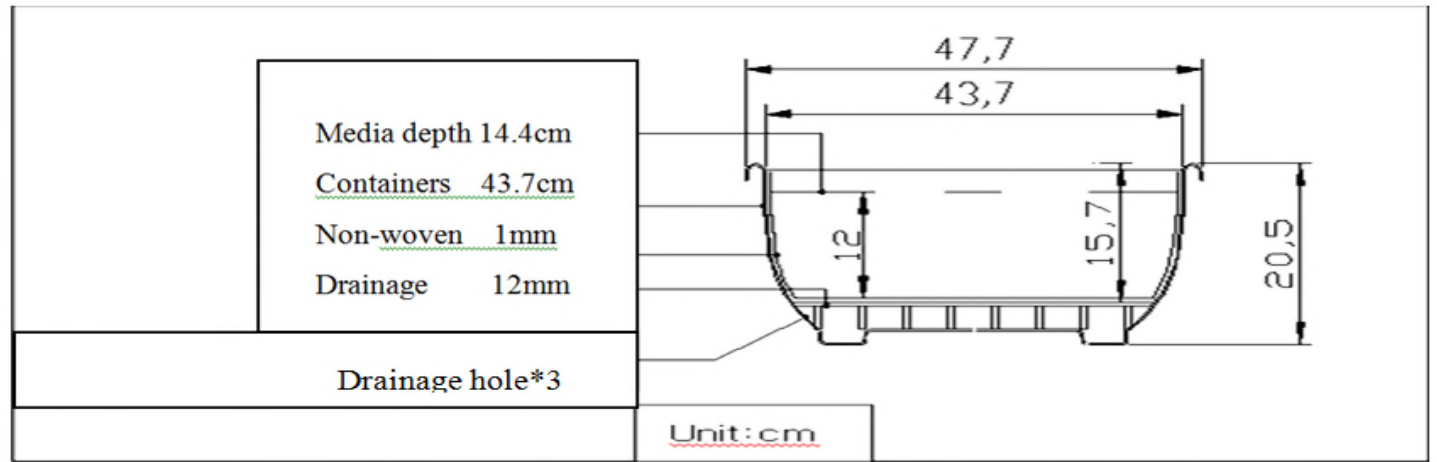

Fig. 4 Cultivation containers' laying drainage board and non-woven cross-section.

Medium. Media (pottery spherical is sludge high temperature kiln porous material) mixing ratio of deliberate industry and research experience selected(Tab.1). Amount of sample media S0 is heavy, $\mathrm{S} 1$ is median, $\mathrm{S} 2$ is light .

Table 1. Prescriptions of medium.

\begin{tabular}{|c|c|c|c|}
\hline No. & S0 & S1 & S2 \\
\hline Media & Pottery spher. $20 \%$,Sandy loam $80 \%$ & Pottery spher. 50\%,S. loam 50\% & Pottery spher. $80 \%$,S. loam $20 \%$ \\
\hline
\end{tabular}

Table 2. Amount of sample media.

\begin{tabular}{|c|c|c|c|}
\hline Medium & Medium volume & Medium weight & Total Medium weight \\
\hline \multirow{2}{*}{$\begin{array}{l}\text { (Pottery spherical 20\% } \\
\text { Sandy loam } 80 \% \text { ) }\end{array}$} & $0.0031 \mathrm{~m}^{3}$ & $2.542 \mathrm{~kg}$ & \multirow{2}{*}{19.406 kg(Heavy) } \\
\hline & $0.0124 \mathrm{~m}^{3}$ & $16.864 \mathrm{~kg}$ & \\
\hline \multirow{2}{*}{$\begin{array}{cc}\text { S1 } & \text { (Pottery spherical 50\% } \\
\text { Sandy loam 50\%) }\end{array}$} & $0.00775 \mathrm{~m}^{3}$ & $6.355 \mathrm{~kg}$ & \multirow{2}{*}{$16.895 \mathrm{~kg}($ Median$)$} \\
\hline & $0.00775 \mathrm{~m}^{3}$ & $10.54 \mathrm{~kg}$ & \\
\hline \multirow{2}{*}{$\begin{array}{c}\text { S2 (Pottery spherical 80\% } \\
\text { Sandy loam 20\%) }\end{array}$} & $0.0124 \mathrm{~m}^{3}$ & $10.168 \mathrm{~kg}$ & \multirow{2}{*}{14.384 kg(Light) } \\
\hline & $0.0031 \mathrm{~m}^{3}$ & $4.216 \mathrm{~kg}$ & \\
\hline
\end{tabular}


Planting Sample. The study selected 8 plant species: Duranta repens, Alpinia speciosa, Murraya paniculata, Portulaca grandiflora, Zoysia matrella, Liriope platyphylla, Podocarpus costalis, and Spathoglottis plicata), each with 9 seedlings, for a total of 72 seedlings. The study was equipped with 3 kinds of plant pots in different media containers $[4,8]$ with plant cultivation and a detailed view of each seedling planted, after cutting bad branches and leggy branches [5-7].

Experiment and Record. This study had 24 sample group (3 Repeat), covering 3 kinds of planting medium and 8 planting kinds, for a total of 72 groups. The experimental construction date was February 13, 2011 [2-5].

pH value measurement method. The electrode method detects the $\mathrm{pH}$ of each sample. The $\mathrm{pH}$ testing equipment is the SUNTEX PH METER TS-110(Fig. 5, 6).

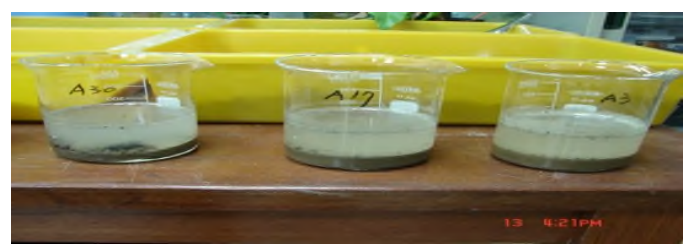

Fig. 5 Pottery spherical medium Sample settle test.

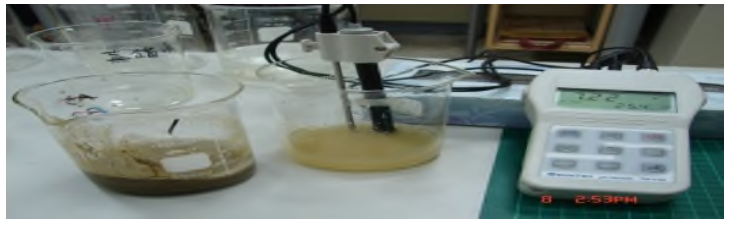

Fig. 6 Pottery spherical medium pH measurement.

\section{Photo data record.}

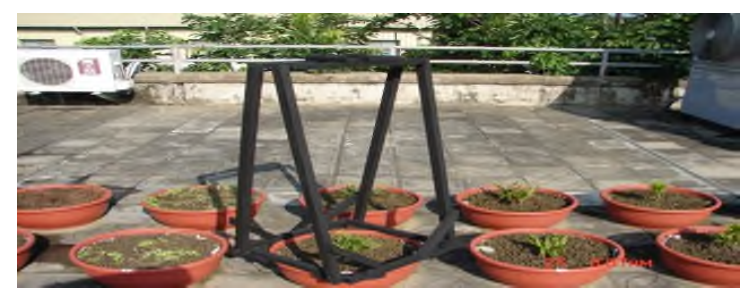

Fig. 7 Record camera tripod
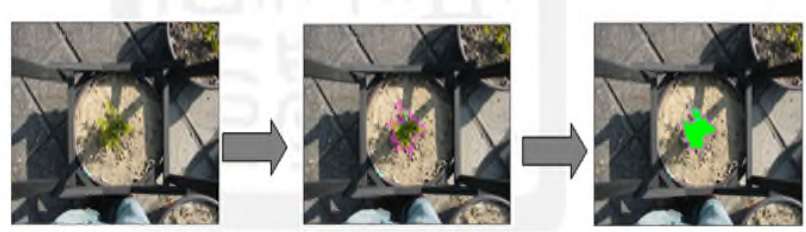

Fig. 8 Green coverage History

Sampling frequency and number. From the date of the beginning of the experiment, for the preceding month the photograph mode recorded the green coverage (Fig.7, 8) [4, 6, 9, 10]. This study conducted the process on July 24, 2011, 160 days later, with a month as an observation period. The camera recorded 6 times and the planting measuring 5 times.

Statistical methods. For the planting medium pH value (Fig. 5, 6), Excel 2013 recorded pH changes made after the graph to understand the trends. The green coverage data was entered into the Excel 2013 file content, in order to analyse the same planting in a different media green coverage of change, so as to find out the ideal cultivated plant cultivation medium $[2-5,7,8]$.

\section{Results and Discussion}

This study focused on lightweight media suitable for landscape plants. For facilities with green roofs, this study added the original medium sandy loam in different proportions of light-weight media, pottery spherical, and sandy loam to examine different proportions after the planting medium (Table 1) was used in the plant along with the growth of high-performance green coverage in different media. The appearance of the physiological condition of the plant can determine the suitability of the planting medium. The ratio of the various media, depending on the experimental results, can help verify the proper proportion of the medium.

Medium pH Value Detection. The $\mathrm{pH}$ of the medium is detected for different media at the beginning, mid-term, and end of the sampling, thus providing the sample testing results (Table 3, Fig. 9). 
Table 3. Medium $\mathrm{pH}$ value detection history.

\begin{tabular}{|c|c|c|c|c|}
\hline \multirow{3}{*}{\multicolumn{2}{|c|}{$3^{\text {Sampling period }} \begin{array}{r}\begin{array}{r}\text { Sate } \\
\text { days }\end{array} \\
\text { days }\end{array}$}} & Beginning & Mid-term & End \\
\hline & & $2011 / 2 / 13$ & $2011 / 4 / 30$ & $2011 / 7 / 27$ \\
\hline & & 1 & 77 & 165 \\
\hline \multicolumn{2}{|c|}{ Medium } & Ave. value 1 & Ave. value 2 & Ave. value 3 \\
\hline S0 & Pottery spherical $20 \%+$ Sandy loam $80 \%$ & 7.31 & 7.38 & 7.49 \\
\hline S1 & Pottery spherical 50\% + Sandy loam 50\% & 7.26 & 7.46 & 7.65 \\
\hline S2 & Pottery spherical $80 \%+$ Sandy loam $20 \%$ & 7.31 & 7.68 & 7.76 \\
\hline
\end{tabular}

When a medium $\mathrm{pH}$ value is detected, most of the medium showed a low-alkaline environment (Table 3, Fig. 9).

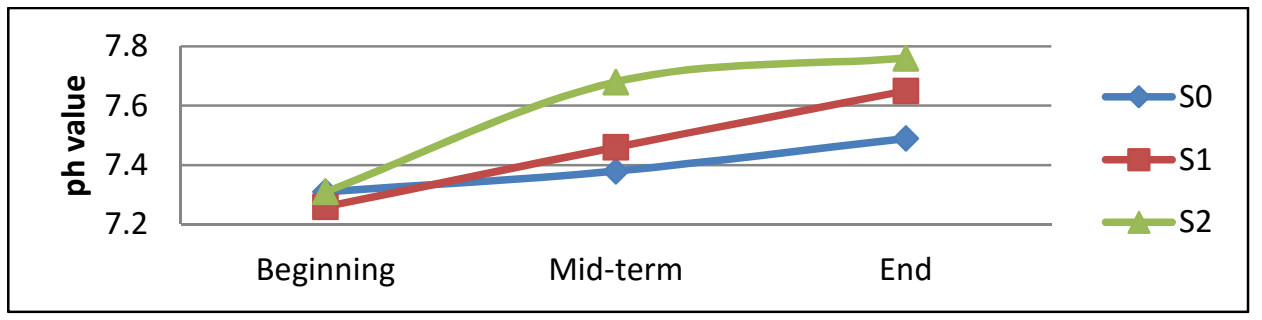

Fig. 9 Medium $\mathrm{pH}$ value detection graph.

\section{Growth Planting History.}

Plant of measurement items.

Table 4. Green coverage

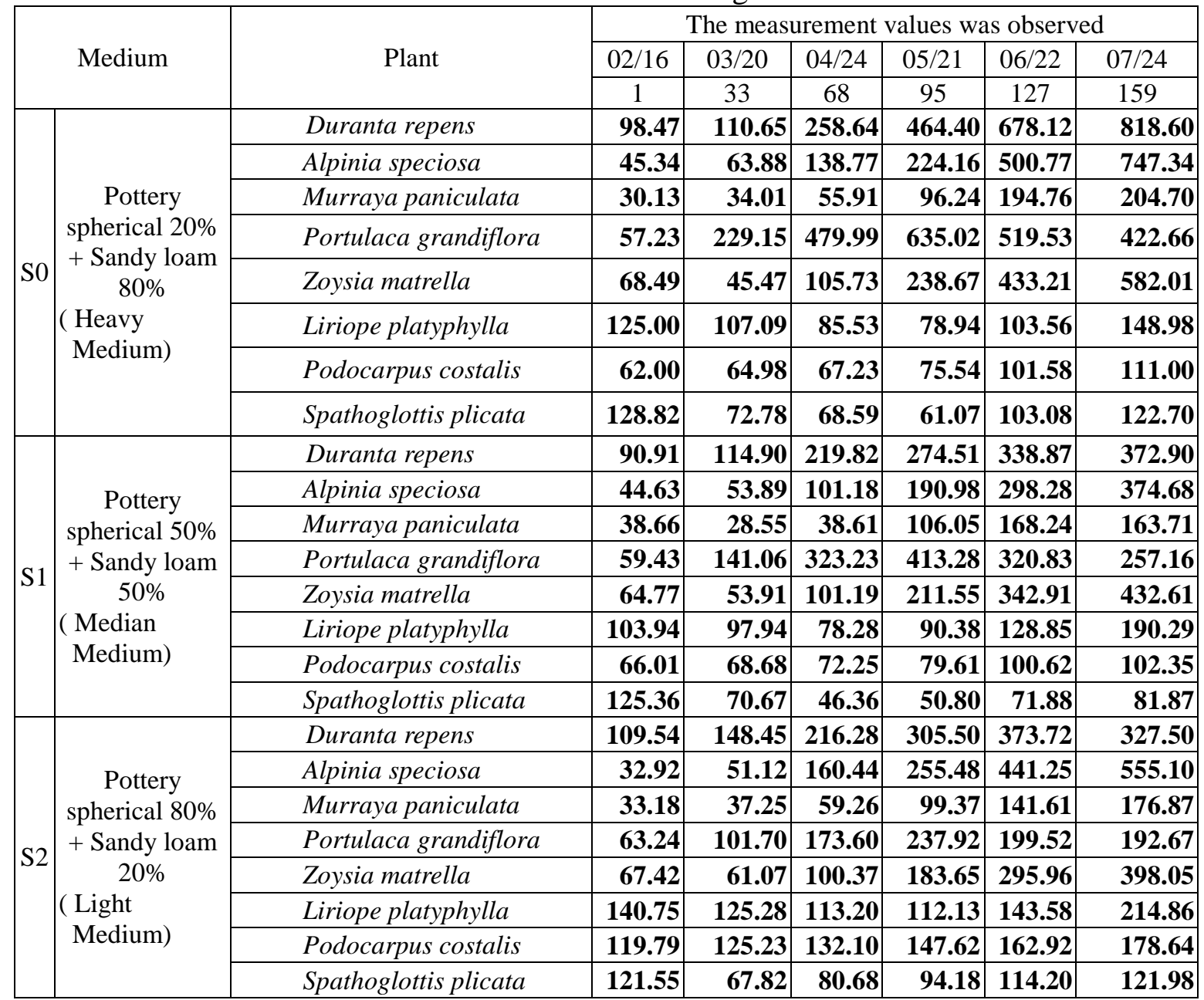


Duranta repens. From the green coverage observed and recorded (Table 4) and the green coverage of the graph (Fig. 10), the growth of Duranta repens S0 (Pottery spherical 20\% + Sandy loam $80 \%$ ) green coverage in the media is significantly superior versus the other media. The study observed a medium to high growth curve for Duranta repens S0. Here, the more than S2 (Pottery spherical $80 \%+$ Sandy loam 20\%) medium and S1 (Pottery spherical 50\% + Sandy loam 50\%) medium Duranta repens height growths are the worst. Thus, S0 is more suitable for Duranta repens growth.

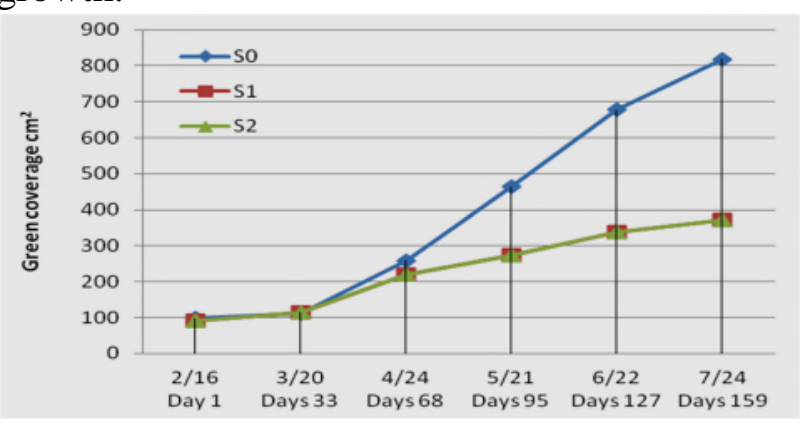

Fig. 10 Duranta repens green coverage curve.

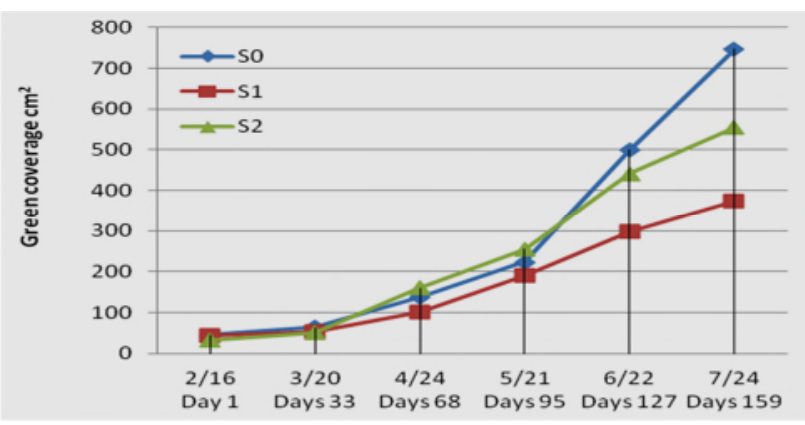

Fig. 11 Alpinia speciosa green coverage curve.

Alpinia speciosa. The S0 medium is more suitable for Alpinia speciosa (Table 4, Fig. 11), where the optimum growth temperature is $20 \sim 30^{\circ} \mathrm{C}$. By observation, the high growth graph shows a proportional relationship between green coverage, with $\mathrm{S} 0$ of the green covering from May. The trend is gradually increasing, where the S2 medium during the planting of the first days 127 slightly slows down away from the green coverage curve. Collocation Alpinia speciosa likes weather that is hot and humid, whereas the general growth of irrigation for Alpinia speciosa still seems inadequate.

Murraya paniculata. In S0 the performance of the media is better than the other two media (S1, S2). By the green coverage of the graph (Table 4, Fig. 12), the S0 and S1 medium in the sample since June shows a slowing increase in green cover health trend, while S2 exhibits a stable growth trend. The rainfall in June and July is more than before; property Murraya paniculata drought, growth temperature for $22 \sim 30^{\circ} \mathrm{C}$, transplanting of Murraya paniculata long time in moist soil, perishable and affect their growth, it can be seen.

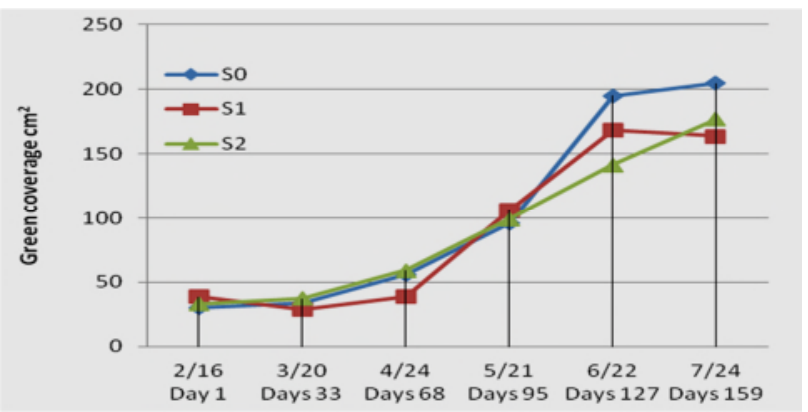

Fig. 12 Murraya paniculata green coverage curve. curve.

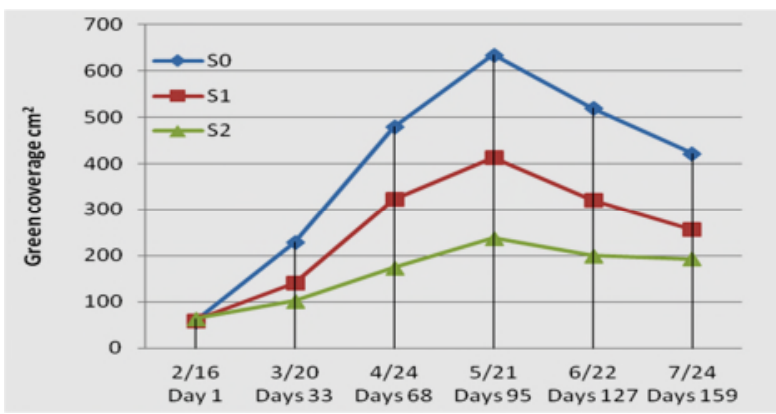

Fig. 13 Portulaca grand. green coverage

Portulaca grandiflora. Portulaca grandiflora is drought-tolerant succulents. The three initial experimental sample green cover approximate values (Table 4), increase green coverage of the fastest medium S0, S1 second, S2 slowest (Fig. 13), the fourth observation after the measurement, due in May, June, July in rainy climate, green coverage of the three curves are showing a downward trend, the decline was minimal S2, S0 is the significant, so the pottery spherical media group for planting Portulaca grandiflora needles when weather conditions and watering should be classified as necessary considerations.

Zoysia matrell. Zoysia matrella growth trend's turf coverage is expressed in Fig. 14. The S0 medium Zoysia matrell green coverage is the maximum, followed by S1 followed, with S2 as the worst. S0, S1, S2 beginning (February to April) green cover rate the difference was not significant (Table 4, Fig. 14). 


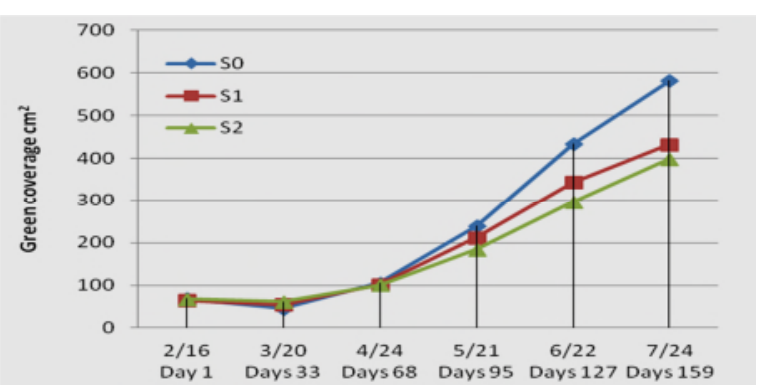

Fig. 14 Zoysia matrell green coverage curve.

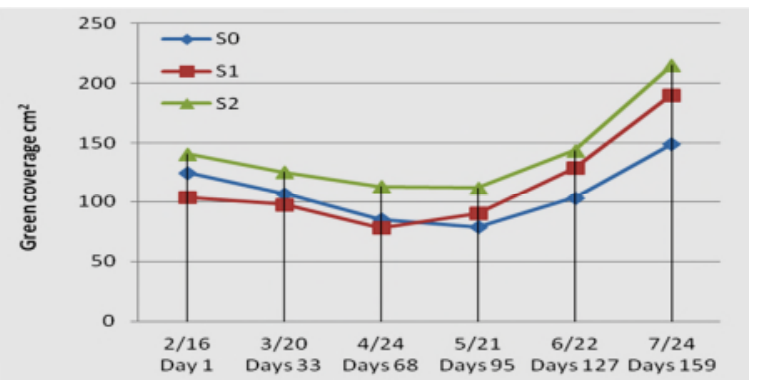

Fig. 15 Liriope platyphylla green coverage curve.

Liriope platyphylla. Liriope platyphylla green coverage observations are in Table 4. The green coverage graph is Fig. 15. The green coverages in the beginning (February to April) for the three samples show a declining state. The $\mathrm{S} 1$ samples beginning green coverage is significantly lower than $\mathrm{S} 0$ and $\mathrm{S} 2$, but for S1 during June to July, the rainy season significantly increased its green coverage beyond S0. The increase in green coverage for Liriope platyphylla is from the best medium of S2, followed by S1, with S0 as the worst (Table 4, Fig. 15).

Podocarpus costalis. Podocarpus costalis green coverage observations are in Table 4. The green coverage graph is Fig. 16. The green coverages for the three samples show a increasing trend similar state. The increase in green coverage for Podocarpus costalis is from the best medium of S2, followed by S0, S1 followed, (Table 4, Fig. 16).
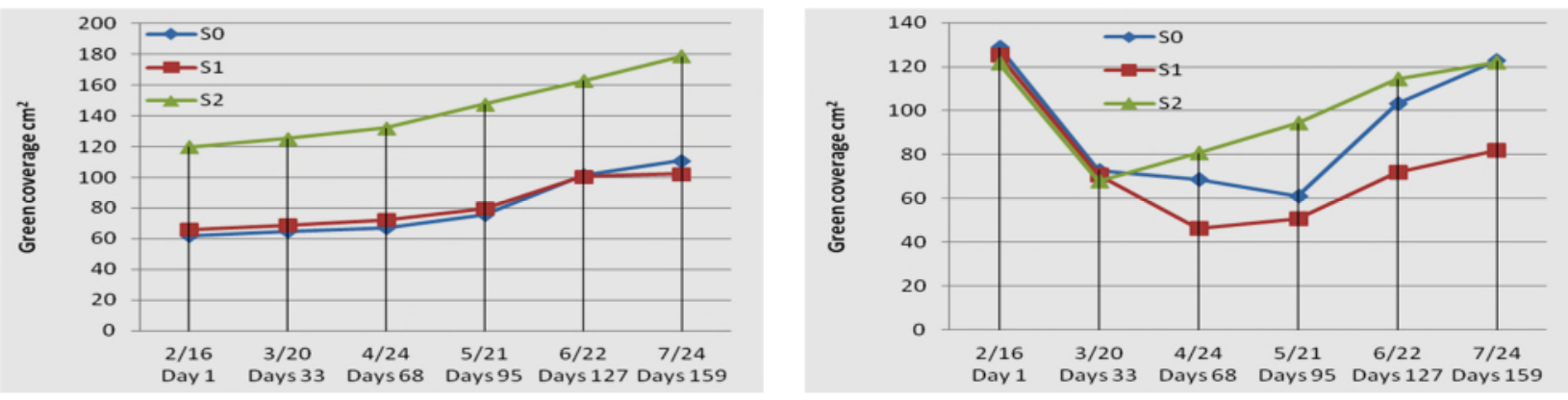

Fig.16 Podocarpus costalis green coverage curve. Fig. 17 Spathoglottis spp. green coverage curve.

Spathoglottis plicata. Beginning with the green coverage as the largest decline (Table 4, Fig. 17). However, for S2, only until its green coverage is days 33 does it see a rising gentle trend. For, S1 there is a slight increase from the days 68 , S0 there is a slight increase from the days 95, and it continues until the end of the experiment observation.

\section{Summary and Conclusion}

In this study we experiment with light-weight pottery spherical medium used in landscape industry in order to find the ideal lightweight media combination that is helpful for plant growth, without the price being high. We mixed light-weight medium with sandy loam for use in landscape construction in southern Taiwan. The prescription for medium $\mathrm{pH}$ value is detected, with most of the medium showing a low-alkaline environment.

We tested 8 plants and 3 medium and tested pottery spherical base, thus achieving the results.

The green coverage for light media S2 (pottery spherical to sandy loam is 8:2) is suitable for Alpinia speciosa the best growth $555.1 \mathrm{~cm}^{2}$, followed is Zoysia matrella the growth $398.05 \mathrm{~cm}^{2}$, with Duranta repens as the third growth $327.5 \mathrm{~cm}^{2}$.

The green coverage for median media S1 (pottery spherical to sandy loam is 5:5) is suitable for Zoysia matrella the best growth $432.61 \mathrm{~cm}^{2}$, followed is Alpinia speciosa the growth $374.68 \mathrm{~cm}^{2}$, with Duranta repens as the third growth $372.90 \mathrm{~cm}^{2}$.

The green coverage for heavy media S0 (pottery spherical to sandy loam is 2:8) is suitable for Duranta repens the best growth $818.60 \mathrm{~cm}^{2}$, followed is Alpinia speciosa the growth $747.34 \mathrm{~cm}^{2}$, with Zoysia matrella as the third growth $582.01 \mathrm{~cm}^{2}$. 
Pottery spherical to sandy loam medium is more suitable for Duranta repens, Alpinia speciosa, and Zoysia matrella with growth.

The ratio of pottery spherical to sandy loam is $2: 8$, thus increasing the coverage and growth for Duranta repens $\left(818.6 \mathrm{~cm}^{2}\right)$, Alpinia speciose $\left(747.3 \mathrm{~cm}^{2}\right)$, Murraya paniculata $\left(204.7 \mathrm{~cm}^{2}\right)$, Portulaca grandiflora $\left(422.06 \mathrm{~cm}^{2}\right)$, Zoysia matrella $\left(582.01 \mathrm{~cm}^{2}\right)$ and Spathoglottis plicata $\left(122.7 \mathrm{~cm}^{2}\right)$.

The prescription, whereby the ratio of pottery spherical to sandy loam is 5:5, is suitable for Duranta repens $\left(372.9 \mathrm{~cm}^{2}\right)$, Alpinia-speciosa $\left(374.68 \mathrm{~cm}^{2}\right)$, Portulaca grandiflora $\left(257.16 \mathrm{~cm}^{2}\right)$, Zoysia matrella $\left(432.61 \mathrm{~cm}^{2}\right)$, whereby the ratio of pottery spherical to sandy loam is $8: 2$, is suitable for Podocarpus costalis $\left(178.64 \mathrm{~cm}^{2}\right)$ and Liriope platyphylla $\left(214.86 \mathrm{~cm}^{2}\right)$. The prescription, whereby the ratio of pottery spherical to sandy loam is $8: 2$, is more suitable for Murraya paniculata and Portulaca grandiflora during the rainy season. The prescriptions, whereby the ratio of light-weight medium is $2: 8$, which is suitable for more kinds of plants. Different media prescriptions are well-grown planting combinations, in which one can choose different plant species based on the environment and in order to create biodiversity. This can be achieved to reduce the building load and may provide a good environment for the growth of plants and create space in favor of green roofs.

\section{References}

[1] J. M. Bousselot, J. E. Klett, R. D. Koski, Moisture content of extensive green roof substrate and growth response of 15 temperate plant species during dry down, Hort Sci. 46(3) (2011) 518-522.

[2] C. C. Chen, L. S. Han, Research of residential area ecological green roof for reduce the heat efficiency in Taichung, Appl. Mech. Mater. 368-370 (2013) 1270-1273.

[3] C. C. Chen, Research of extensive green roof (Spring) for create comfortable environment in Taiwan City, Appl. Mech. Mater. 749 (2015) 420- 424.

[4] C. C. Chen, C. L. Chen, Research of environmental friendly materials (recycling waste) is applied to green roof in planting and growth index difference, Adv. Educ. Sci. 10 (2015) 331- 336.

[5] C. C. Chen, Research of green roof heat accumulating and cooling efficiency in urban, J. Architecture Plan. 16(2/3) (2015) 135-150.

[6] K. Durhman Angela, D. B. Rowe, C. L. Rugh, Effect of substrate depth on initial growth, coverage, and survival of 25 succulent green roof plant taxa, Hort Sci. 42(3) (2007) 588-595.

[7] R. Giridharan, S. S. Y. Lau, S. Ganesan, Nocturnal heat island effect in urban residential developments of Hong Kong, Energ Build.ings ,37(9) (2005) 964- 971.

[8] Y. J. Lin, 2012, Study of sustainable type container extensive green roof, Chin Kung University, Doctoral Dissertation, Tainan, Taiwan (R.O.C.)

[9] S. Onmura, M. Matsumoto, S. Hokoi, Study on evaporative cooling effect of lawn gardens, Energ. Build. 33 (2001) 653-666.

[10] E. Palomo, D. Barrio, Analysis of the green roofs cooling potential in buildings. Energ. Build. (27) (1998) 179-193.

[11] T. Sendo, M. Kanechi, Y. Uno, I. Noboru, Evaluation of growth and green coverage of ten ornamental species for planting as urban rooftop greening, J. Jpn. Soc. Hortic. Sci. 79(1) (2010) 69-76.

[12] T. Takakura, S. Kitade, E. Goto, Cooling effect of greenery cover over a building, Energ. Build. 31 (2000) 1-6. 